\title{
Villavicencio: de nacimiento espontáneo a ciudad intermedia actual ${ }^{*}$
}

\author{
Villavicencio: From Spontaneous Birth to \\ a Current Intermediary City
}

Villavicencio: de nascimento espontâneo a cidade intermediária atual

\author{
Carlos Cortés Acuña * \\ Yonier Castañeda-Pérez ${ }^{* *}$
}

Recibido: 27 de septiembre de 2019

Aprobado: 4 de mayo de 2020

https://doi.org/10.12804/revistas.urosario.edu.co/territorios/a.8284

Para citar este artículo:

Cortés Acuña, C., \& Castañeda-Pérez, Y. Villavicencio: de nacimiento espontáneo a ciudad intermedia actual. Territorios, (43-Especial), 1-24. https://doi.org/10.12804/revistas.urosario.edu.co/territorios/a.8284

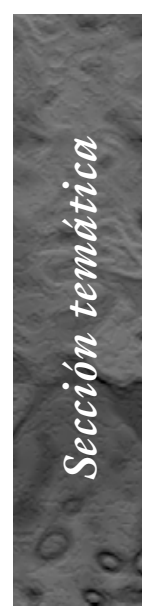

* Este artículo es producto del proyecto de investigación doctoral Geohistoria del espacio urbano y reconfiguración territorial 1980-2019: los fragmentos urbanos cerrados de vivienda en Villavicencio, Colombia, que el autor Carlos Cortés Acuña adelanta en el Doctorado en Estudios Territoriales de la Universidad de Caldas, Colombia.

** Universidad de Caldas, Manizales, Colombia. Correo electrónico: cortesac@hotmail.com. ORCID: https://orcid.org/00000001-5559-1926

*** Universidad de Caldas. Manizales, Colombia. Universidad La Gran Colombia, seccional Armenia. Correo electrónico:yonierc@gmail. com ORCID: https://orcid. org/0000-0003-04840253 
Palabras clave

Ciudad intermedia;

Villavicencio;

ecogénesis territorial; globalización; forma urbana.

Keywords

Intermediary city; Villavicencio; territorial ecogénesis; globalization; urban form.

Palavras-chave

Cidade intermediária; Villavicencio; ecogênese territorial; globalização; forma urbana.

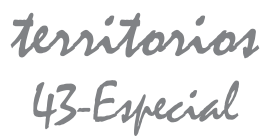

RESUMEN

La ciudad de Villavicencio tiene unas características particulares por su ubicación y condición actual, pero sobre todo por su configuración territorial a partir de una geohistoria de la economía política, relacionada con los llanos orientales de Colombia, su dependencia estrecha con la capital, Bogotá, y con la zona andina del país. Este artículo hace una revisión de los principales hechos territoriales del proceso de formación de la ciudad desde sus orígenes prehispánicos en el territorio Guayupe, hasta la imposición de la cultura llanera en una ciudad poblada de inmigrantes del altiplano cundiboyacense, pasando por las haciendas coloniales, los fenómenos de migración y violencia, y los diferentes factores económicos que impulsaron el surgimiento de una ciudad intermedia con gran influencia en el panorama nacional.

\section{ABSTRACT}

The city of Villavicencio has particular characteristics due to its location and its current state, but especially for the territorial configuration from a geo-history of the political economy, due to its relationship with the eastern plains of Colombia, and its close dependence to Bogotá and the Andean area of the country. This article presents a review of the main territorial facts of the formation process of the city from its pre-Hispanic origins in the Guayupe territory to the imposition of the Ilanera culture in a city populated by Cundiboyacense immigrants and influenced by the colonial haciendas, the phenomena of migration and violence, and the different economic factors that boosted the emergence of an intermediate city with great influence on the national scene.

\section{RESUMO}

A cidade de Villavicencio tem umas características particulares pela sua localização, pela sua condição atual, mas especialmente pela configuração territorial a partir de uma geo-história da economia política em seu interior graças a sua relação com as planícies orientais da Colômbia e a sua dependência estreita com a capital Bogotá e com a zona andina do país. Este artigo faz uma revisão dos principais factos territoriais do processo de formação da cidade desde suas origens pré-hispânicas no território Guayupe, até a imposição da cultura llanera em uma cidade populada de imigrantes do planalto cundiboyacense, passando pelas fazendas coloniais, os fenômenos de migração e violência, e os diferentes fatores econômicos que impulsionaram o surgimento de uma cidade intermediária com grande influência no panorama nacional. 


\section{Introducción}

Si bien los esfuerzos por reconstruir la historia urbana de Villavicencio parten de su origen formal con la refundación en la época republicana, es posible reconocer que esta tiene orígenes anteriores como territorio de intercambio comercial entre los indígenas habitantes de la región este del piedemonte de la cordillera oriental colombiana y las comunidades muiscas del centro de Colombia. Este hecho territorial marca la pauta del presente artículo, que busca explicar las condiciones particulares de una ciudad que es un cruce de senderos llaneros que conectan con el mundo, cuya compleja historia no ha terminado de consolidarse. Con posteridad a este proceso ancestral, en 1845, según Salamanca Uribe (2009), se realiza una fundación oficial en lo que teóricamente se reconoce como un espacio concebido (Lefebvre, 2013) que modifica las formas espontáneas de su nacimiento por los de una cuadrícula que ordena los terrenos a la usanza de la Colonia española. Todo esto permite afirmar, siguiendo a AprileGniset (1992), que Villavicencio, como la mayoría de las ciudades latinoamericanas, no nace exclusivamente del capitalismo, sino del feudalismo medieval. Como otras poblaciones del país, la ciudad crece a partir de un impulso del sector primario exportador hacia el interior y el exterior de Colombia (Aprile-Gniset, 1992), además por fenómenos de violencia, narcotráfico y extracción minera, que continúan hasta la actualidad.

Vale la pena precisar que el fundamento teórico utilizado en la aproximación a la geohistoria del espacio urbano de la ciudad de Villavicencio es la ecogénesis territorial (Raffestin, 1986). Esta metodología permite construir los aparatos conceptuales para la comprensión de una realidad actual a partir de su génesis territorial. La ecogénesis territorial se da cuando la semiósfera de un grupo, es decir, el conjunto de signos que caracterizan una sociedad, se introduce y relaciona con un espacio geográfico particular. De tal manera, las semiósferas traducen y transforman el espacio mediante elementos formales que semiotizan el lugar y separan los significados como membranas semipermeables que controlan el acceso de formas y significados exteriores. Estas membranas representan la unión con un mundo diferente y por tal motivo son las encargadas de precisar una cultura determinada que, según la escala formal, puede definir múltiples entidades territoriales y sus yuxtaposiciones. Es decir, no se puede comprender el territorio sin tener en cuenta su ecogénesis; de igual manera, los procesos de planificación serán solo proyectos sobre el espacio, si no tienen en cuenta las diferentes semiósferas implicadas.

Ahora bien, en el espacio geográfico donde se localiza la ciudad de Villavicencio, se presenta una reunión de caminos tersitorias 43-Especial 
${ }^{1}$ Estimaciones de población 1985-2005 y proyecciones de población 2005-2020 total municipal por área (DANE)

\section{territorias 43-Especial}

que provienen no solo de los llanos orientales colombianos, sino también de las más importantes ciudades de la región que se ubican al borde de la cordillera oriental. El hecho de que este siga siendo un puto obligado de tránsito para llegar al centro del país, destaca y da valor a las experiencias indígenas que ancestralmente ya lo utilizaban como conector con las principales, dominantes y más avanzadas culturas andinas.

Por su parte, la ciudad también ha tenido una condición cíclica en la medida en que partió de un estadio morfológico de desorden y espontaneidad —donde se fueron ubicando posadas y centros de servicios para los caminantes y arrieros de ganado- a una formación de tipo colonial con un damero clásico, que rige el nuevo orden impuesto. Posteriormente, y de manera tardía, se intentó un desarrollo de carácter moderno, ordenado y regulado que pronto se perdió por el distanciamiento del Estado y el triunfo de la cultura capitalista neoliberal. Esto dio vía a un crecimiento espotáneo en la medida en que la ciudad fue desarrollándose según las necesidades de los habitantes.

Como con todas las historias de la región indígena colonizada, la de $\mathrm{Vi}$ llavicencio es una historia dividida: una ancestral difícil de conocer con certeza y otra, la de los colonizadores, que no es más que su propia historia determinada según sus necesidades, realidades, creencias y valores. El presente artículo pretende encontrar en los intersticios de la construcción histórica moderna los hitos territoriales que forman su realidad actual; se parte de una semiotización del espacio que responde a la fusión entre naturaleza y cultura, y de una ecogénesis que transforma lo exterior y lo indeterminado en interno y protegido, que genera a su vez un sentido de propiedad simbólica y material.

\section{Ciudad intermedia actual}

La zona urbana de Villavicencio, capital del departamento del Meta y principal ciudad de la Orinoquía y la Amazonía colombianas, está ubicada en el centro geográfico del país (figura 1). Cuenta con 452472 habitantes (Alcaldía de Villavicencio, 2016), albergando el 66,57\% de la población del departamento del Meta. ${ }^{1}$ Tiene una extensión aproximada de 1328 $\mathrm{km}^{2}$, una altura sobre el nivel del mar de $457 \mathrm{~m}$, una temperatura media de $28^{\circ} \mathrm{C}$ y está ubicada a 71,7 km de Bogotá.

La ciudad se expande desde la montaña, en la ladera este de la cordillera oriental, hasta el llano, donde cuenta con posibilidades de crecimiento. Está limitada al norte por el río Guatiquía y al sur por el río Ocoa, dichos límites naturales han sido rebasados por la presión inmobiliaria existente en toda la ciudad, lo que ha incrementado notablemente su baja densidad habitacional al extenderse por más de $15 \mathrm{~km}$ a partir del centro fundacional, ubicado en el piedemonte. 
Figura 1. Ubicación de Villavicencio
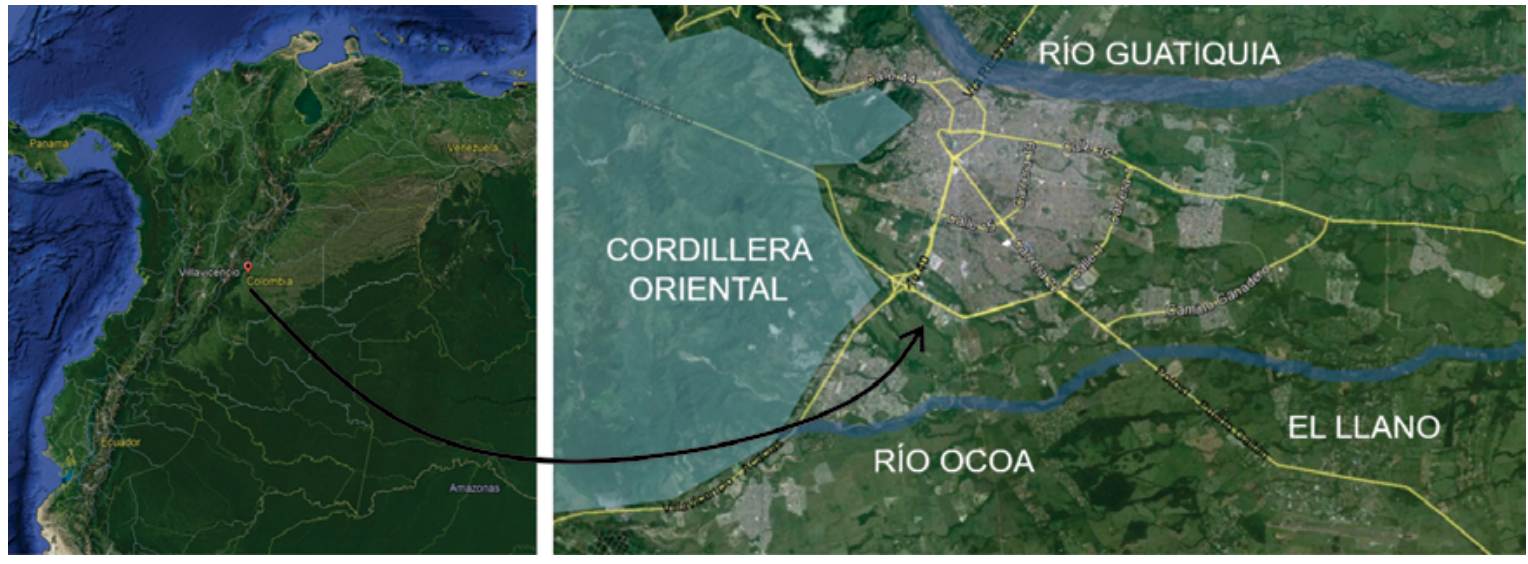

Fuente: elaboración propia a partir de aerofotografías de Google Earth en 2017.

\section{Hechos territoriales}

\section{Origen prehispánico}

Según los documentos históricos existentes sobre la ciudad de Villavicencio, que hablan de su etapa prehispánica embrionaria, se puede decir que este espacio de piedemonte, junto con vastas zonas llaneras - antes de la colonia española- era un territorio, porque era un espacio geográfico habitado, vivido, trabajado y luchado por poblaciones guayupe, comunidades establecidas con ciertos órdenes sociales y grupos bélicos de difícil reducción para los españoles (Franco, 2017), quienes, a diferencia de la actual subutilización agrícola del suelo, tenían sofisticados sistemas que hacían más productiva la tierra (Gómez López \& Cavalier de Ferrero, 1998).
Para Espinel Riveros (1989), los historiadores asignan un área de ocupación inicial de aproximadamente $22000 \mathrm{~km}^{2}$, comprendida entre la cordillera oriental y la desembocadura del río Ariari (figura 2), cuya extensión es más o menos el $26 \%$ del total de lo que hoy es el departamento del Meta que abarca, en su parte noroccidental, la ubicación actual de la ciudad de Villavicencio. Según la autora, hay algunas evidencias que prueban la existencia vida en la región desde el siglo XIV; sin embargo, la certeza de su existencia y los hallazgos documentados corresponden con la llegada de los españoles, quienes dan fe de un pueblo organizado con costumbres propias en múltiples crónicas de viaje.

Según Melo (1978) los guayupes habitaban entre la región del Ariari y Villavicencio; no obstante, la falta de información dificulta establecer la localización territarios 43-Especial 
Figura 2. Posible localización guayupe, siglo XVI

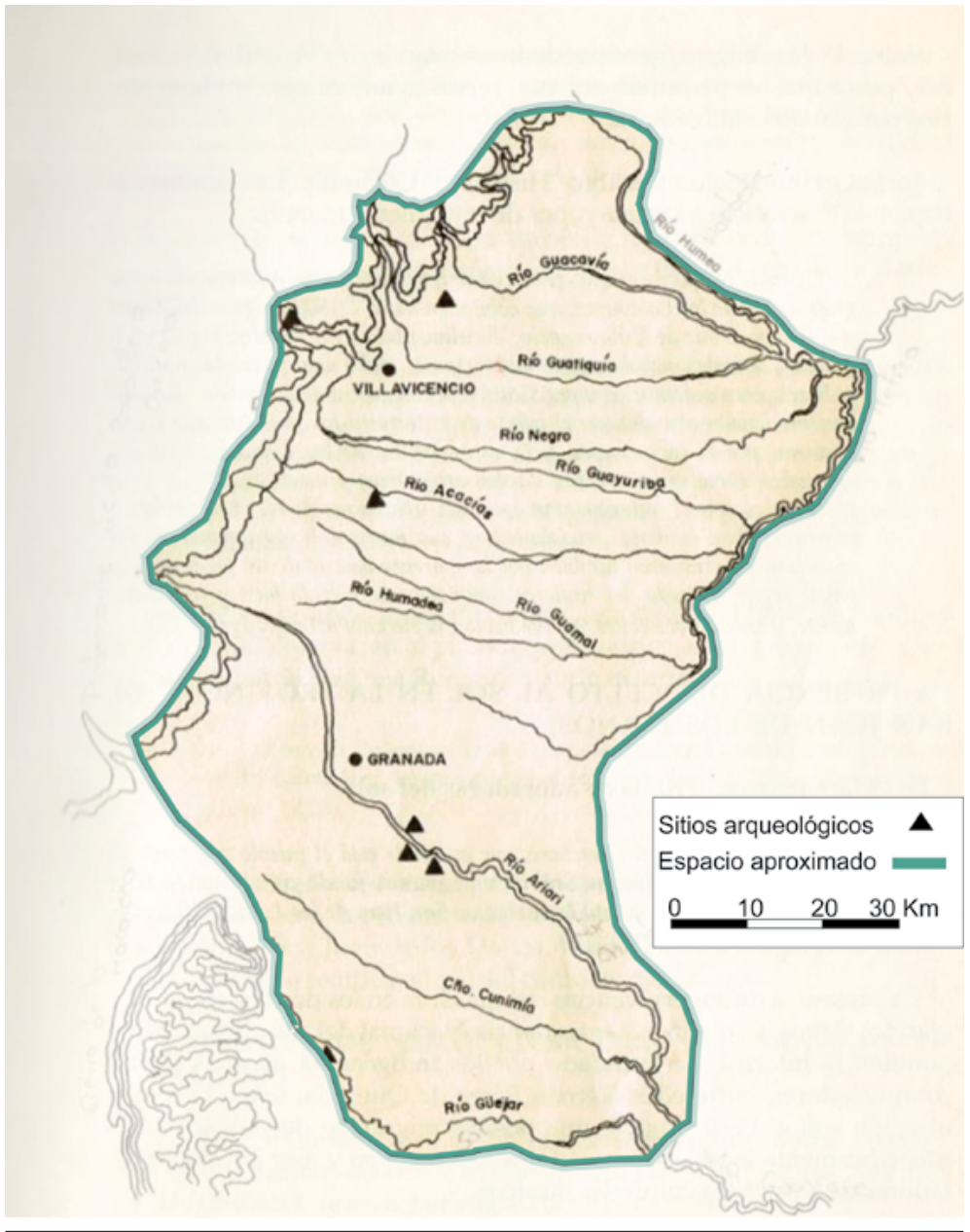

Fuente: adaptado de Espinel Riveros (1989, p. 23).

tersitarias 43-Especial exacta de las comunidades en lo que hoy es Villavicencio. A partir de ello y de hallazgos arqueológicos de tipo lítico y vegetal, Espinel (1989) deduce que dichas comunidades realizaban intercambios comerciales con los chibchas del altiplano.
Dichos intercambios, relatados por los conquistadores españoles, se realizaban posiblemente en tierras de lo que hoy se conoce como Guayabetal en el departamento de Cundinamarca, sobre la actual vía que comunica a Villavicencio con Bogotá, a $20 \mathrm{~km}$ aproximadamente de la capital del Meta. Allí, los indígenas guayupes intercambiaban plumas, cueros de felino, totumos, maíz y algodón, entre otros, por mantas, cerámicas, esmeraldas, sal y oro provenientes de la cordillera y del centro del país (Salamanca Uribe, 2009). Se marca así el origen de Villavicencio, una zona de encuentro de culturas a través de largos y sinuosos caminos, principalmente motivados por un intercambio comercial que continúa en la actualidad. Una etapa que, como muchas otras en el continente, fue cortada abruptamente y de manera artificial por la llegada de los españoles.

\section{Incursión de la Colonia española}

Debido a la fama de oro y riqueza esparcida por las comunidades que tenían intercambio con los guayupes, en época de la conquista hubo varias incursiones a los llanos en busca de la leyenda de El Dorado (Ruiz Churión, 1992). Dichas expediciones comenzaron hacia $1530 \mathrm{y}$ encontraron un poblado con características de ciudad que primero fue denominada Nuestra Señora de La Asunción y luego Nuestra Señora de La Fagua; en 1556, Juan de Avellaneda, en una expedición comandada por Nicolás de Federmán, 
fundó en el mismo lugar la ciudad de San Juan de los Llanos (Rausch, 2011). Esta población se ubicaba al sur de lo que hoy es Villavicencio, entre San Martín y el río Ariari (figura 3). Según las crónicas, este poblado fue determinante para situar geográfica y estratégicamente a Villavicencio y sus orígenes, ya que era un punto central de comercio entre las comunidades andinas y todos los actuales llanos colombo-venezolanos. Posiblemente desde allí partían caravanas de comercio hacia el altiplano, usando caminos ancestrales indígenas (Espinel Riveros, 1989), pasando por poblados como Guayabetal.
Para Ruiz Churión (1992), el proceso de incursión de la colonización española en estos territorios se divide en dos partes. La primera fue asesina y sangrienta, proveniente de los Andes. En esta, hacia mediados de 1800, los españoles prácticamente habían acabado con el pueblo guayupe mediante la esclavización, el maltrato y las enfermedades, en la búsqueda de las riquezas descritas en la leyenda de El Dorado. La segunda, se relaciona con las comunidades religiosas que, a partir de resguardos y misiones, se ubicaron en gran parte del territorio de lo que hoy es el departamento del Meta.

Figura 3. Ubicación de San Juan de los Llanos en relación con la hacienda Apiay y la localización actual de Villavicencio

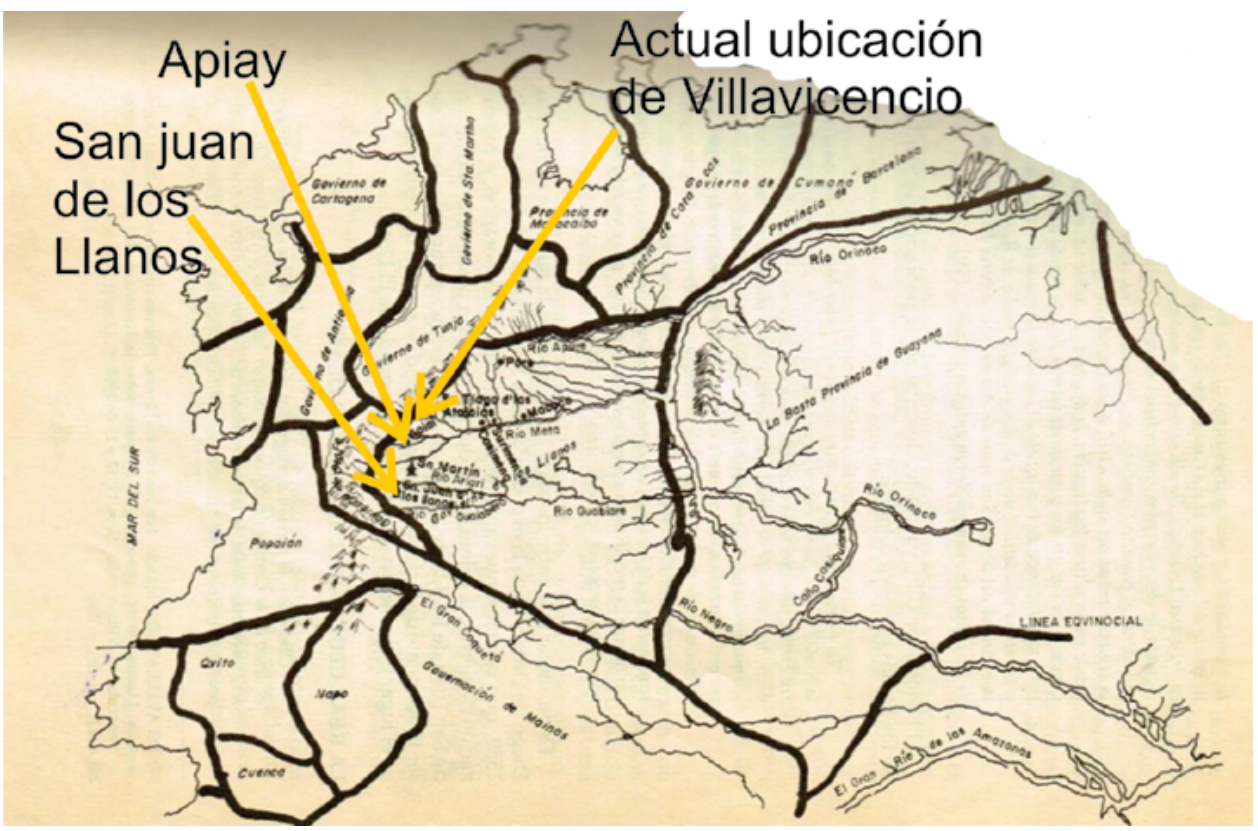

Fuente: adaptado de Espinel Riveros (1989, p. 37). 


\section{La época de las haciendas}

Según Espinel Riveros (1989), la misión jesuita entró a los llanos en 1625 y fundó varias haciendas, una de ellas fue la de Apiay en 1740 (figura 4), que llegó a ser una de las más prósperas, cuya localización es en lo que actualmente corresponde a Villavicencio.

En esta etapa histórica, debido a la presión demográfica de la zona andina y la necesidad de colonizar espacios pretendidos por los españoles, los jesuitas impulsaron las capitulaciones y licencias para fundar poblaciones por las condiciones de fertilidad de la tierra y su aptitud para la crianza de ganado. De esta manera, surgieron incursiones como la de Gonzalo Jiménez de Quezada en 1569 con la subsiguiente mutación de poblados itinerantes a poblaciones mestizas estables que empiezan a tener un desarrollo socioeconómico basado en la ganadería. De este proceso surge la ciudad de San Martín (al lado de San Juan de los Llanos) como un primer polo de desarrollo, que fue reemplazado por Villavicencio, varios años después, por su localización estratégica.

Según Franco (2017), desde el siglo XVII existía una relación comercial desigual

Figura 4. Ubicación de la Hacienda Apiay y la actual posición de Villavicencio

tersitorias 43-Especial

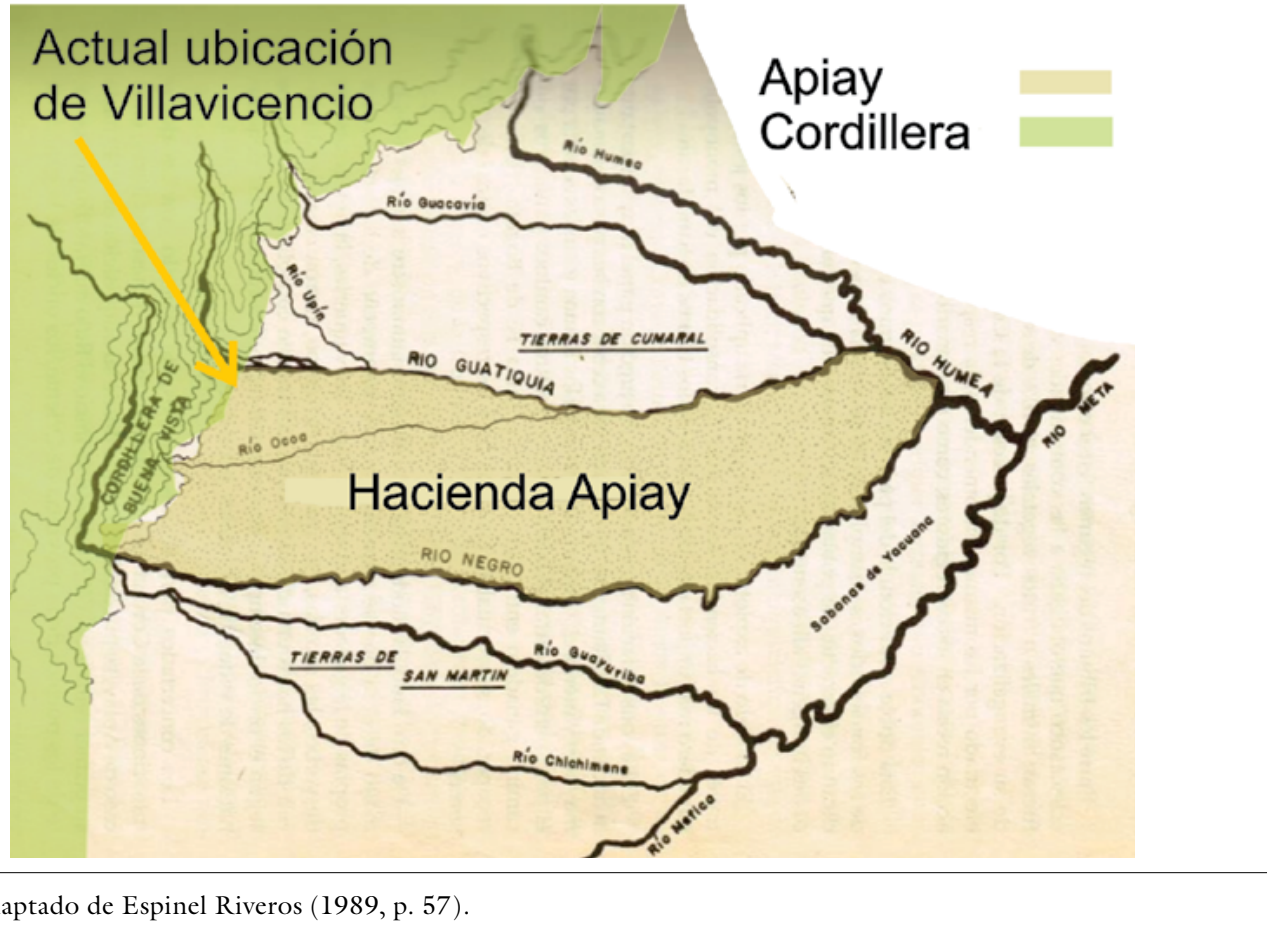


entre Bogotá y Villavicencio, operada principalmente por misiones religiosas que tenían un deseo civilizador a través de la religión, que se repartieron una región hasta entonces poco productiva en términos agrícolas o esclavistas, debido a la belicosidad de sus pobladores. Entre estas misiones estaban los agustinos, los franciscanos, los dominicos y los jesuitas que, como se indicó, se encargaron de fundar haciendas en el piedemonte dentro de la zona de estudio (figura 5).

En el mismo sentido, Pérez Ángel (1988) apunta que las misiones fueron las instituciones más importantes en el dominio imperial sobre el territorio llanero, especialmente la de los jesuitas desde
1620 hasta 1767. De esta relación entre trabajo principalmente ganadero y la cultura española, surgieron los estereotipos actuales del hombre llanero: a caballo dedicado al manejo de reses. Es así como se fue formando un grupo de edificaciones donde se retomaban fuerzas antes de iniciar el ascenso de las escarpadas y peligrosas lomas de la cordillera oriental. Este aglomerado se ubicó justo antes de empezar la zona montañosa, al lado del caño Gramalote, del cual tomo su primer nombre.

Se resalta la importancia estratégica de la Hacienda Apiay a partir de un fragmento escrito por el historiador Rueda Enciso (1987):

Figura 5. Misiones y poblados españoles en los llanos hacia 1760

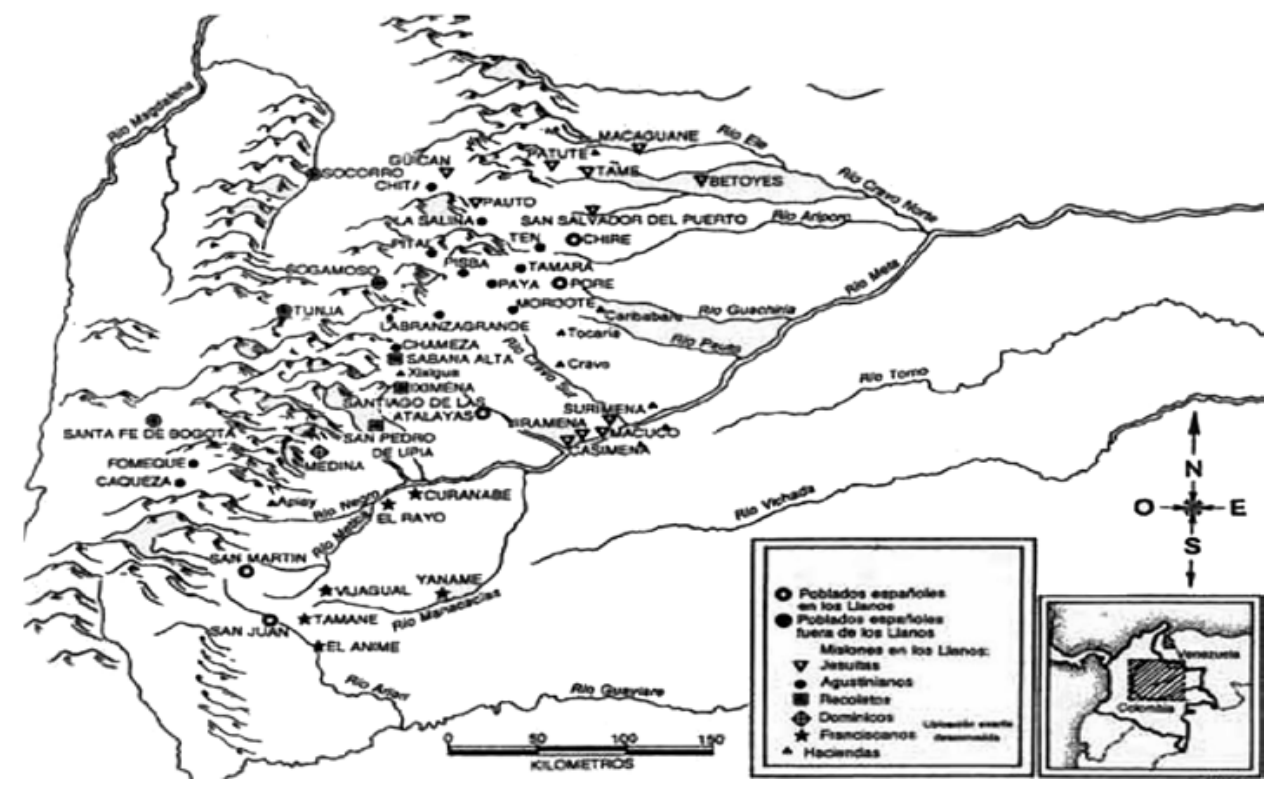

Fuente: Rausch (1994, p. 92$)$. 
Como los ignacianos no poseían una hacienda en el piedemonte del Meta, en donde se podría reponer el ganado para iniciar el ascenso hacia el principal centro administrativo del Virreinato (...) compraron en el decenio de 1774 la Hacienda de Apiay entre los ríos Ocoa y Guayuriba, sitio realmente estratégico para comprar ganado, pues como en un principio no había vía de unión entre Santa Fe, San Martín y San Juan de los Llanos, y era bastante difícil para los habitantes de aquellas regiones transportar el ganado a Santiago de las Atalayas y de allí a Tunja, preferían vender los semovientes a los jesuitas en dicha hacienda, la cual quedaba a ocho días de la ciudad de Santa Fe. También permitió a los hijos de Loyola su extensión hacia el alto río Meta (p. 11).

Se ratifica que la venta, el intercambio y el cruce de caminos como lugar final de un trayecto e inicio de otro fueron los principales factores que paulatinamente dieron lugar a la formación de Villavicencio como un asentamiento permanente. Desde esta época, se puede deducir la existencia del mencionado caserío de Gramalote en la confluencia de los caminos al lado del caño del mismo nombre. Una primera fundación de hecho es relatada por Salamanca Uribe (2009):

Espadas y blasones, escudos y armaduras, hidalgos y clérigos, actas y pergaminos: todos brillaron por su ausencia en la fundación de Villavicencio. En su lugar, estuvieron arrieros sudorosos, proclives al alcohol y a la reyerta, que terminaban la jornada en una posada a la orilla del caño Gramalote, junto al cerro de La Estanzuela, procedentes de algún punto de los llanos, tras el ganado que conducían durante varios días hasta Bogotá. Para algunos, una fundación deslucida y prosaica; para otros, este nacimiento de hecho - que dio lugar a divergencias sobre la fecha de fundación- representa la esencia de los primeros años de la vida republicana de un país construido por arrieros y comerciantes (p. 2).

\section{Refundación: nuevo espacio concebido}

En 1850 el congreso granadino creó el distrito parroquial de Villavicencio que involucraba al antiguo corregimiento de Gramalote. El historiador Ortega Ricaurte (1943) anota que en 1860 se adscribió Villavicencio como parte del primer departamento de Bogotá, lo que demuestra un origen temprano de la relación de dependencia que este territorio ha tenido con la capital y la influencia marcada desde el comienzo de su historia.

Los suministros y los lugares de encuentro, socialización y distinción se realizan en los núcleos urbanos nacientes, marcados desde siempre por la diferenciación de clases y poderes. El núcleo urbano definido, en tanto espacio concebido (Lefebvre, 2013), involucra lo que hoy es el centro de la ciudad (figura 6). De 
esta porción de la ciudad se tienen pocos registros gráficos históricos por lo que se hace imprescindible acudir a crónicas y dibujos realizados por habitantes de aquellos tiempos.

Salamanca Uribe (2009) relata un intento de planificación ordenada con un centro o cabecera desde donde se dirigirían todas las labores de las haciendas llaneras:

En enero de 1845 el Gobernador de Cundinamarca ordenó al jefe político de Cáqueza “delinear la población que se está formando en Gramalote escogiendo un punto conveniente por su situación y abundancia de aguas, trazando una plaza espaciosa y por lo menos las ocho calles que a ella deben conducir con una anchura de 25 a 30 varas y designando en la plaza los lugares que deben ocupar la capilla, la casa cural, la escuela, la cárcel y la casa municipal". En 1850, la ciudad fue rebautizada con el nombre de Villavicencio, en honor al quiteño Antonio Villavicencio y Verástegui y dos años después el corregimiento fue elevado a cabecera de Cantón siendo designado Nicolás Díaz como su primer alcalde (p. 3).

El siguiente hito que modifica estructuralmente las relaciones sociales y la morfología de la ciudad tiene que ver con la llegada, nuevamente, de comunidades religiosas como los monfortianos, los hermanos de la sabiduría y los hermanos de la Salle implantados esta vez en un

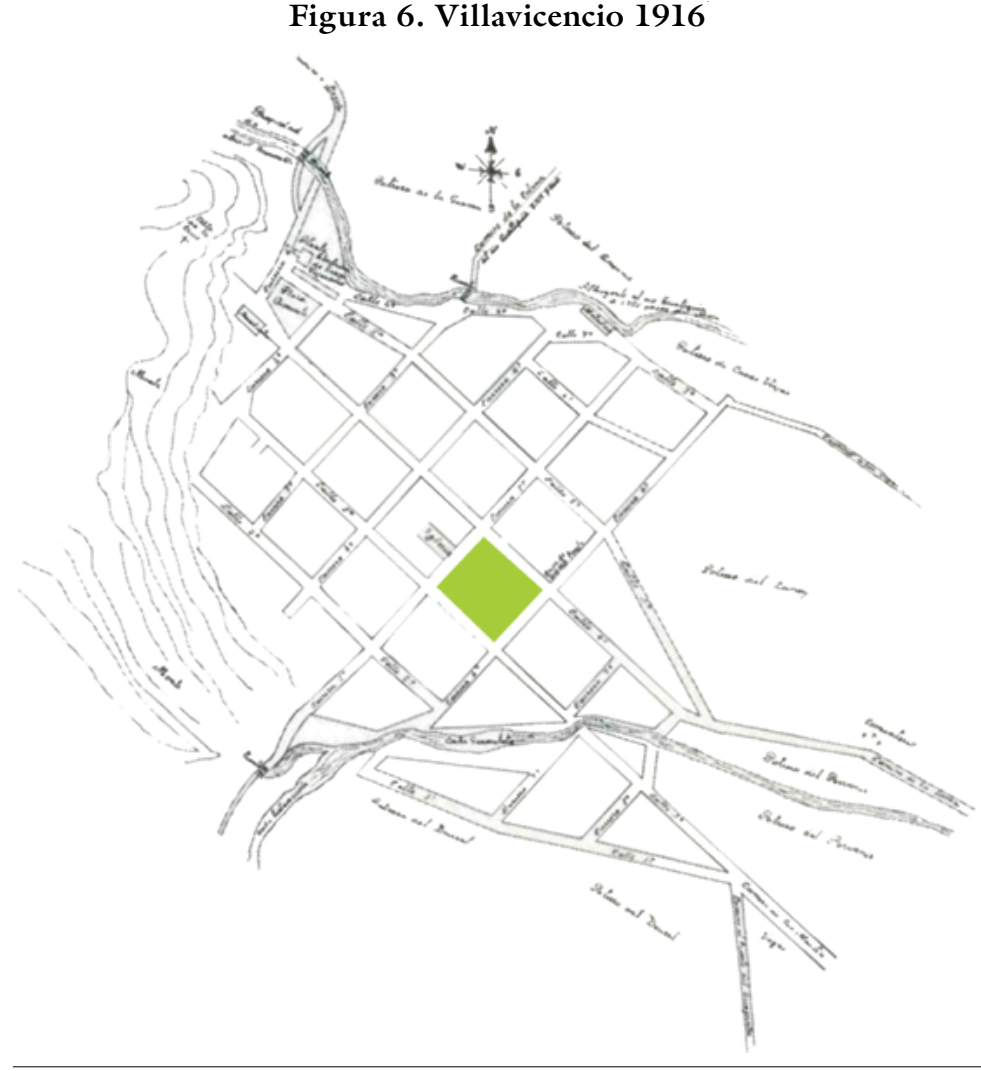

Fuente: adaptado del plano del archivo de la Fundación para el Archivo Fotográfico de la Orinoquia (FAFO).

ambiente urbano y quienes enfocaron sus esfuerzos en la educación y modernización social a partir de la cultura (Espinel Riveros, 1989). Estas comunidades fundaron colegios, teatros y hospitales, entre otros, además de traer ideas modernas sobre el ser y estar en una ciudad, lo cual, naturalmente, se vislumbra como un motor de cambio que incentiva al resto del país a ver a la región no solo como una despensa agrícola comandada por aventureros que territorios 43-Especial 
vivían entre animales y salvajes, sino como un territorio de frontera, articulación e intercambio de donde empezaban también a surgir iniciativas propias de desarrollo.

\section{La conexión con el mundo}

Para 1924 los ganaderos, comerciantes y el intendente Luna Ospina - quien instaló un peaje-, consiguieron juntar los recursos suficientes para construir lo que se puede denominar como el primer carreteable que conectaría la ciudad con el centro del país (Salamanca Uribe, 2009). Esto impulsó una dinámica económica globalizada que se mantiene hasta el siglo XXI — aún la conexión de Villavicencio con el mundo no se produce a través de medios aéreos ni fluviales, sino a través del transporte pesado de carga y pasajeros que utilizan la carretera-.

La siguiente etapa de definición de la vía liderada por el Gobierno nacional, que unió definitivamente a la región con el centro del país comenzó en 1928 y terminó en 1936 (Espinel Riveros, 1989); sin embargo, la vía estaba trazada por un camino que seguía un terreno montañoso e inestable que no era fiable y sigue sin serlo.

El mejoramiento definitivo comenzó en la década de 1990, que coincide con un auge demográfico y un intercambio comercial más representativo con 20000 cabezas de ganado, 270000 toneladas de arroz y 40000 toneladas de aceite y palma (Baquero Nariño, 1990), con un transporte de aproximadamente 65500 vehículos entre semana y 200000 los fines de semana (Instituto de Turismo del Meta, 2014; Secretaría de Planeación Municipal de Villavicencio, 2013). Con esto se reafirma la importancia de la ciudad y la movilidad que hay entre los llanos y la capital del país, teniéndola como punto articulador no solo en sentido BogotáVillavicencio sino, necesariamente, con las zonas de ganadería, agricultura y minería que se encuentran en diferentes espacios geográficos de la región orinoquense.

\section{Inmigración y neocolonización}

En este punto se pueden destacar dos elementos fundamentales que dan cuenta de la internacionalización y globalización de la región. En primer lugar, la formación colonial enfocada en la producción ganadera y su comercialización, dependiente no solo de otras regiones del país, sino de otros países como España y Portugal. En segundo lugar, las pequeñas bonanzas que proporcionaron las explotaciones de los árboles nativos enfocados en el mercado internacional y su consecuente desaparición debido a factores exógenos. Aprile-Gniset (1992) así lo reflexiona:

De tal modo que la "modernización" económica de principios del presente siglo, que se deriva del impulso del sector primario exportador y de la integración del país a los mercados mundiales de crudos (minería de dragados, exploraciones petrolíferas, 
exportación bananera o cafetera, etc.), incide poderosamente en una consolidación del parque urbano y en una ampliación y extensión de la red de centros; es cuando se verifica un primer nivel de urbanización. No obstante, este fenómeno ocurre en forma lenta, moderada y gradual y, por lo tanto, en nada revoluciona la estructura y la morfología de un determinado centro, ni trastorna su capacidad de absorción de lo nuevo y su indispensable adecuación (p. 594).

Esta dinámica demuestra la afirmación de Aprile-Gniset (1992) al plantear que en Colombia durante 100 años se fundan más ciudades que durante toda la época colonial (figura 7), en especial debido a una formación agraria, que hace que algunas ciudades tradicionales desaparezcan.

En los párrafos precedentes se puede observar el origen socioeconómico de Villavicencio como una población de servicios primarios, un lugar de encuentro de caminos y de paso que se mantiene en mayor o menor medida hasta hoy. Sin embargo, se evidencia un desarraigo debido a la inmigración, la economía de servicio y el extractivismo, así como por el turismo. Todo ello configura el territorio villavicense actual. Además de las actividades económicas mencionadas, es importante registrar que los productos como la quina y el caucho fueron factores de atracción de población hacia la región de piedemonte (Espinel Riveros, 1989); no obstante, como ya lo anotaba en su
Figura 7. Formación espacial agraria 1850-1950

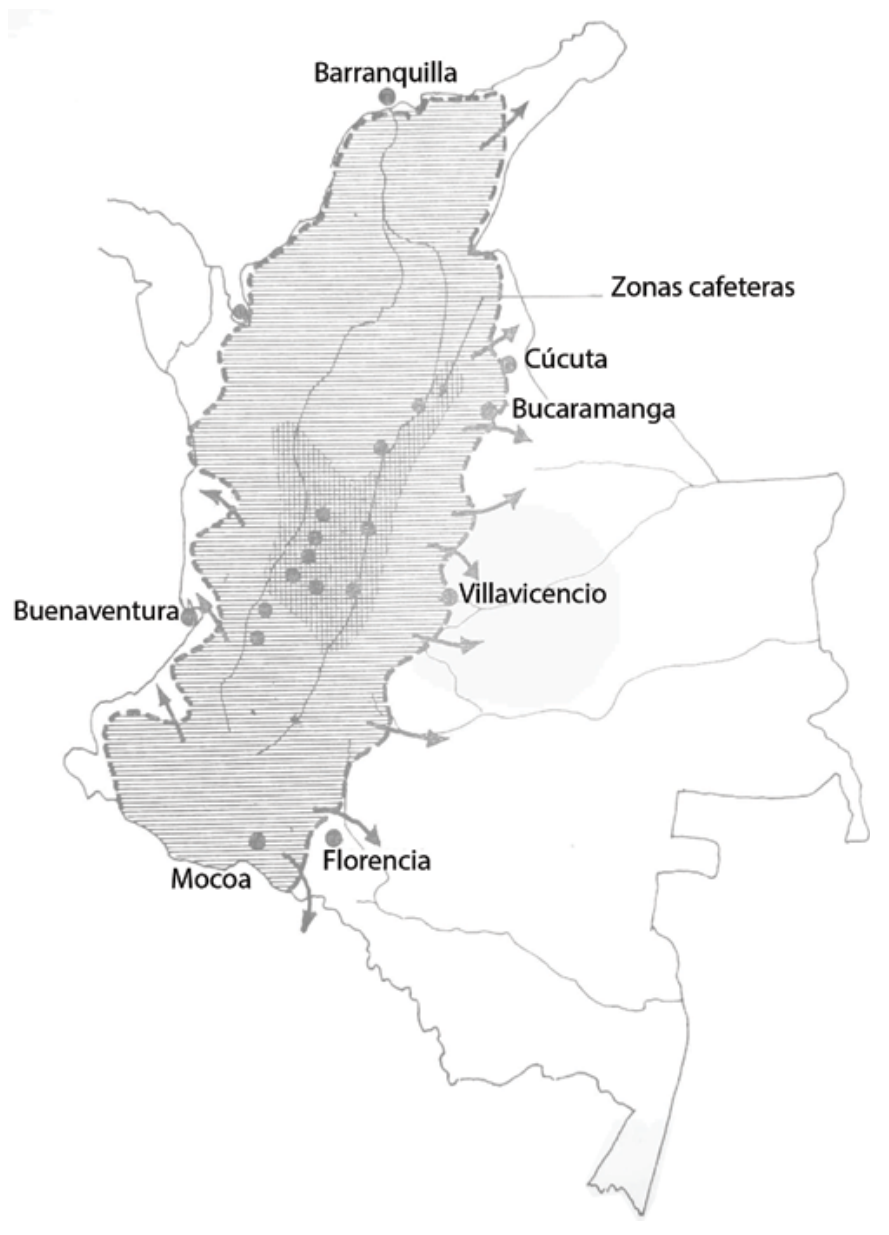

Fuente: Aprile-Gniset (1992, p. 17).

diario el explorador Gutiérrez de Alba (1871), estos productos estaban destinados a desaparecer:

He empleado el día en mis apuntes y en investigar la manera de extraer el cautchut del árbol que lo produce, y que se tersitorias 43-Especial 


\section{territorias} 43-Especial encuentra por aquí en grandísima abundancia. Consiste este absurdo sistema en derribar el árbol para extraerle el jugo con más facilidad, despoblando de este modo los bosques de un vegetal tan útil y privándose para en delante de sus productos. Esto mismo hacen con los árboles de quina, de modo que, dentro de algunos años, habrá desaparecido para Colombia estas dos grandes fuentes de riqueza (p. 109).

La desaparición de estos cultivos y la reducción de los precios internacionales de la quina produjeron un cambio de perspectiva, que se enfocó en la producción del caucho entre 1870 y 1910, lo cual creó un ambiente de migración constante y prosperidad que decayó por la facilidad de las importaciones y el descenso de los precios del caucho (Espinel Riveros, 1989). Es así como se vivió aquella nueva colonización espontánea surgida al otro lado de la frontera que produce el piedemonte, definiendo los territorios a partir del mercado nacional e internacional, integrándolos a los mercados mundiales. Esto se decanta, según Barbosa (1988), en tres elementos históricos que tienen influencia regional. El primero, con una ola de migración relacionada con la Guerra de los Mil Días y la fiebre cauchera (19001904); el segundo, con la crisis agraria y la guerra con el Perú (1932-1933), y, por último, la guerra civil no declarada de la década de los 50. Estos tres escenarios formaron lo que dicho autor denomina la "ruda personalidad del llano".
Estas primeras muestras de relevancia, modernización y desarrollo de la región y la ciudad comienzan a generar una explosión demográfica sin precedentes. Según Rausch (1954), Villavicencio creció de 4736 a 24318 habitantes en 20 años, entre 1918 y 1939, promovida, entre otras cosas, por el gobierno central que estimuló la colonización como parte de una estrategia de avance y soberanía en territorios poco explorados, que produjo una migración procedente de los departamentos del Tolima, Antioquia, Boyacá, Cundinamarca, los santanderes y el Valle del Cauca.

\section{Petróleo, narcotráfico y otros}

Uno de los elementos más relevantes en este análisis socioeconómico temporal fue la aparición del petróleo en los llanos orientales, que modificó una vez más y de manera radical las condiciones evolutivas naturales de una población que, como ya se advirtió, sufrió grandes impactos exógenos que la modificaron profundamente, a la vez que le dieron el carácter particular de hoy.

Según Espinel Riveros (1989), las expectativas de encontrar petróleo en la región datan de 1920 cuando la compañía Engineering \& Exporting anunciaba la posibilidad de la existencia de este hidrocarburo. Posteriormente, se hacen exploraciones nuevamente infructuosas en 1940, pero no fue sino hasta finales de los años 60, después de la creación de Ecopetrol en 1951, que el Meta empezó 
a ser un gran productor de petróleo en el país (Rausch, 2011). En este proceso, el departamento del Meta fue tomando lugares intermedios hasta llegar a ser el mayor productor de crudo en Colombia, reemplazado brevemente por el Casanare y nuevamente retomando su posición privilegiada hasta el día de hoy. Este auge que comienza a reflejarse en Villavicencio como principal núcleo urbano receptor de empresas y productor (mediador) de mano de obra calificada se da en los 80 , que, como muchos otros elementos, coinciden con los cambios socioeconómicos radicales que llevaron a la ciudad a la realidad urbana que hoy es objeto de indagación y reflexión.

Por otro lado, en medio de una tregua con la violencia vivida con el nacimiento del Frente Nacional —inicios de los años 60 - los grupos guerrilleros que continuaban existiendo se convirtieron en un desgaste para el Gobierno y fueron atacados con toda la fuerza del Estado. En 1964, embisten y matan a la mayoría de los rebeldes de Marquetalia, que se consideraban una república independiente; los sobrevivientes formaron el grupo guerrillero FARC con ideología marxista inspirados por otras revoluciones de América (Rausch, 2011).

Años después, a causa del mencionado grupo insurgente y de los ejércitos particulares formados por los terratenientes para mantener su hegemonía (paramilitares), estos se convirtieron en la causa del incremento migratorio hacia la ciudad. Otro aspecto relevante en la economía (globalizada) de los llanos, con repercusiones importantes en Villavicencio, es el narcotráfico. Según Duarte y Vargas (2013), la llegada del narcotráfico se puede observar desde los años 70 con el auge de sembrados de marihuana. Sin embargo, los mayores efectos sobre la sociedad villavicense se dieron en los años 90, con el cultivo y procesamiento de la coca y la aparición de los carteles con tecnología internacional adecuada para su producción.

La relación de dicha actividad con los escenarios globalizados tiene su máximo esplendor en la década mencionada y, mientras la droga considerada ilegal salía de los llanos al resto del mundo, estos grupos devolvían ingentes capitales que modificaron la realidad de una ciudad convirtiéndola en un centro de inversión y gasto de grandes cantidades de dinero, así como en un lugar donde reflejar el estatus de algunas familias que surgían, debido a estos nuevos negocios. Dichos excedentes de dinero eran evidentes en una población aun pequeña, en términos de comportamiento social y en las inversiones realizadas en la ciudad. En tal sentido, Rausch (2011) anota:

Comenzando con la afluencia del dinero de la droga: desde la marihuana hasta la cocaína, los urbanizadores de Bogotá y otros lugares comenzaron a construir en la ciudad nuevos barrios residenciales, con edificios con estilos más modernos para albergar a la creciente población. Pronto, tersitarios 43-Especial 


\section{territorias} 43-Especial al zinc y al barro los remplazaron nuevos materiales, como el bloque, el ladrillo, el cemento y las tejas de Eternit, y la pintura remplazó a la rústica cal. Las cocinas se hicieron más funcionales, y más higiénicos los servicios sanitarios. Las viviendas de los barrios más acomodados eran más cómodas, agradables y costosas. Los pobres, entretanto, que carecían de títulos a la tierra y no pagaban impuestos, invadieron las zonas más deleznables de Villavicencio, construyendo tugurios similares a los existentes en las ciudades colombianas del altiplano (pp. 173-174).

A pesar de haber resaltado en repetidas ocasiones el carácter de economía terciaria de la región, vale la pena anotar que hubo industrias que tuvieron algo de éxito en Villavicencio. En 1944 se construyó una industria cervecera y, más adelante, una desmotadora, una planta de refrigeración de cárnicos y varios molinos de arroz. Todas estas industrias cesaron sus actividades con el paso del tiempo, excepto algunos molinos que subsisten en las áreas de la ciudad que aún tienen un uso de suelo industrial.

En definitiva, la industria, motor principal de formación de ciudades, no fue en Villavicencio un factor que influyera en su crecimiento ni en su desarrollo u origen, en consonancia con Aprile-Gniset (1992), quien advertía que en Colombia la migración y el auge de las ciudades no tienen que ver con la industrialización, sino con múltiples factores que confluyen.
Finalmente, hay que mencionar el turismo, que se ha convertido en uno de los motores de crecimiento de $\mathrm{Vi}^{-}$ llavicencio, que se refleja en la cantidad de construcciones hoteleras formales e informales que existen, como las grandes fincas reconvertidas en sitios de atracción “ecológica" — una actividad que resulta hoy tan importante como la agricultura, el petróleo, la ganadería y los demás elementos económicos predominantes de la región presentes en el imaginario de los villavicenses-. Esto como resultado de la mejora sustancial de la carretera que une a la ciudad con Bogotá, a la construcción de centros comerciales y a los avances en la infraestructura hotelera.

\section{Violencia, inmigración y formación urbana definitiva}

El fenómeno de La Violencia que tuvo apogeo entre los años 50 y 60, con una confrontación entre seguidores de los partidos Liberal y Conservador, dejó una estela de violencia que se refundó constantemente con influencias internacionales, en reflejo de posiciones antagónicas mundiales entre capitalismo y comunismo. Estas confrontaciones, sin mayores reflexiones, llegaron al territorio y se mantuvieron en el tiempo a pesar de lo anacrónico de sus discursos. A pesar de que la violencia fue y es generalizada en toda Colombia (principalmente en las zonas rurales), los llanos orientales y Villavicencio, en particular, han sido una de las regiones 
que más la han sufrido: desplazamientos, asesinatos y clima de guerra instaurado. Como resultado, se anota que la ciudad pasó de 24000 habitantes en 1938 a 33000 en 1951 y a 58000 en 1964, lo que la convierte en la ciudad con la mayor tasa de crecimiento poblacional de Colombia -78\%- (Espinel Riveros, 1989).

En consecuencia, la zona urbana de la ciudad pasó de 43 manzanas en 1937 a 82 en 1958 y a 321 en 1964 (Ojeda, 2000). Esto ocurrió debido a la tecnificación de los planes reguladores inspirados en el modernismo, con énfasis en la jerarquización de las vías arterias, el uso de curvas y diagonales, que cambiaron el estilo colonial por el francés e inglés. En consecuencia, la ciudad tuvo un nuevo empuje de crecimiento espontáneo sin recursos y con una planificación incipiente que aumentó los suburbios y las viviendas autoconstruidas ubicadas principalmente sobre los ejes viales que fueron y son aún los rectores de crecimiento más representativos de la ciudad. Estas infraestructuras se amontonaban en lugares insalubres y peligrosos sin ningún seguimiento institucional (Rausch, 2011) a pesar de la existencia de un plan regulador de Villavicencio (figura 8), frente al cual Aprile-Gniset (1992) anota:

El plan regulador de Villavicencio, del año 44 (con firma de Eduardo Delgadillo), con evidentes "préstamos" del urbanismo inglés de esa época, reminiscencias de Haussman, sin que falten influencias
Figura 8. Plan regulador de Villavicencio

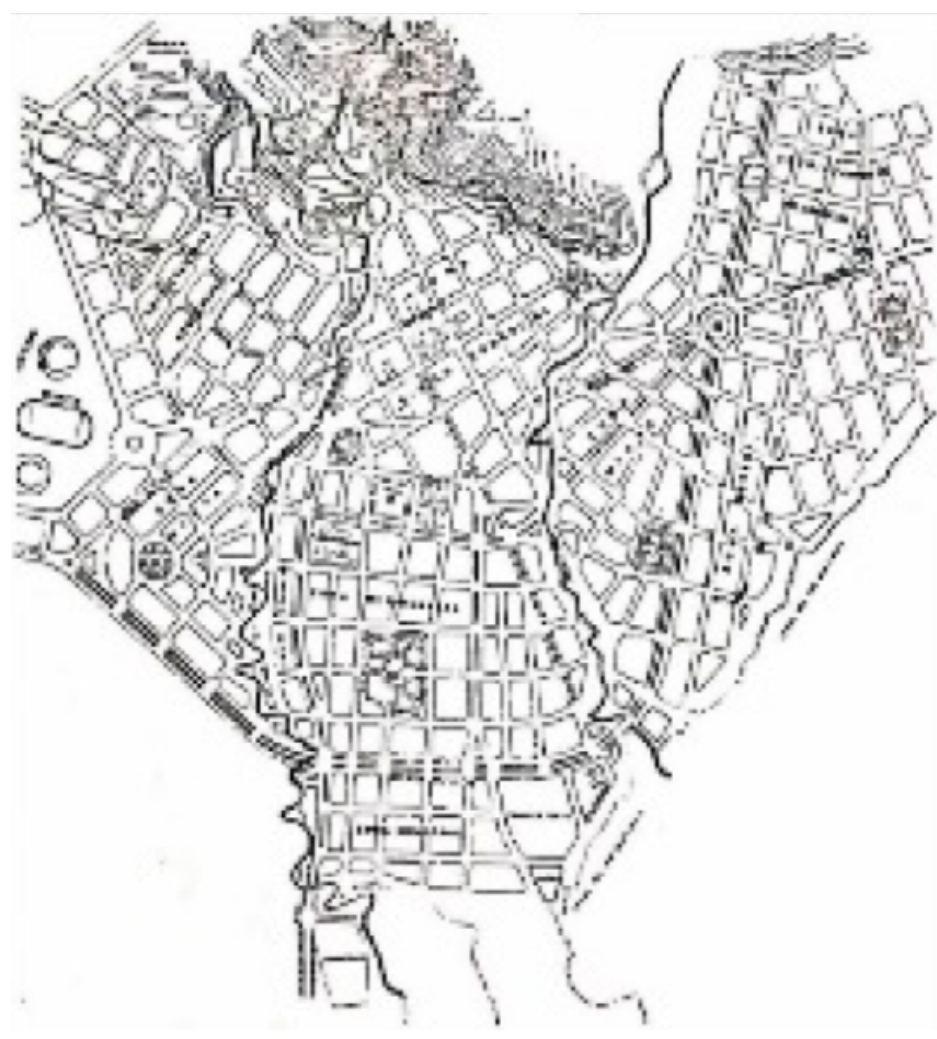

Fuente: Aprile-Gniset (1992, p. 109).

norteamericanas: abundan los espacios libres y públicos y se consideran unas quince plazas y plazoletas de las más variadas formas y dimensiones. Estos planos reguladores consideran tanto el ensanche como la adecuación y modernización del núcleo existente, prevén la localización de nuevos equipamientos colectivos y preconizan una drástica sectorización y zonificación de usos, reforzadas por un reglamento (p. 110). territorios 43-Especial 
Figura 9. Mapa crecimiento de la ciudad

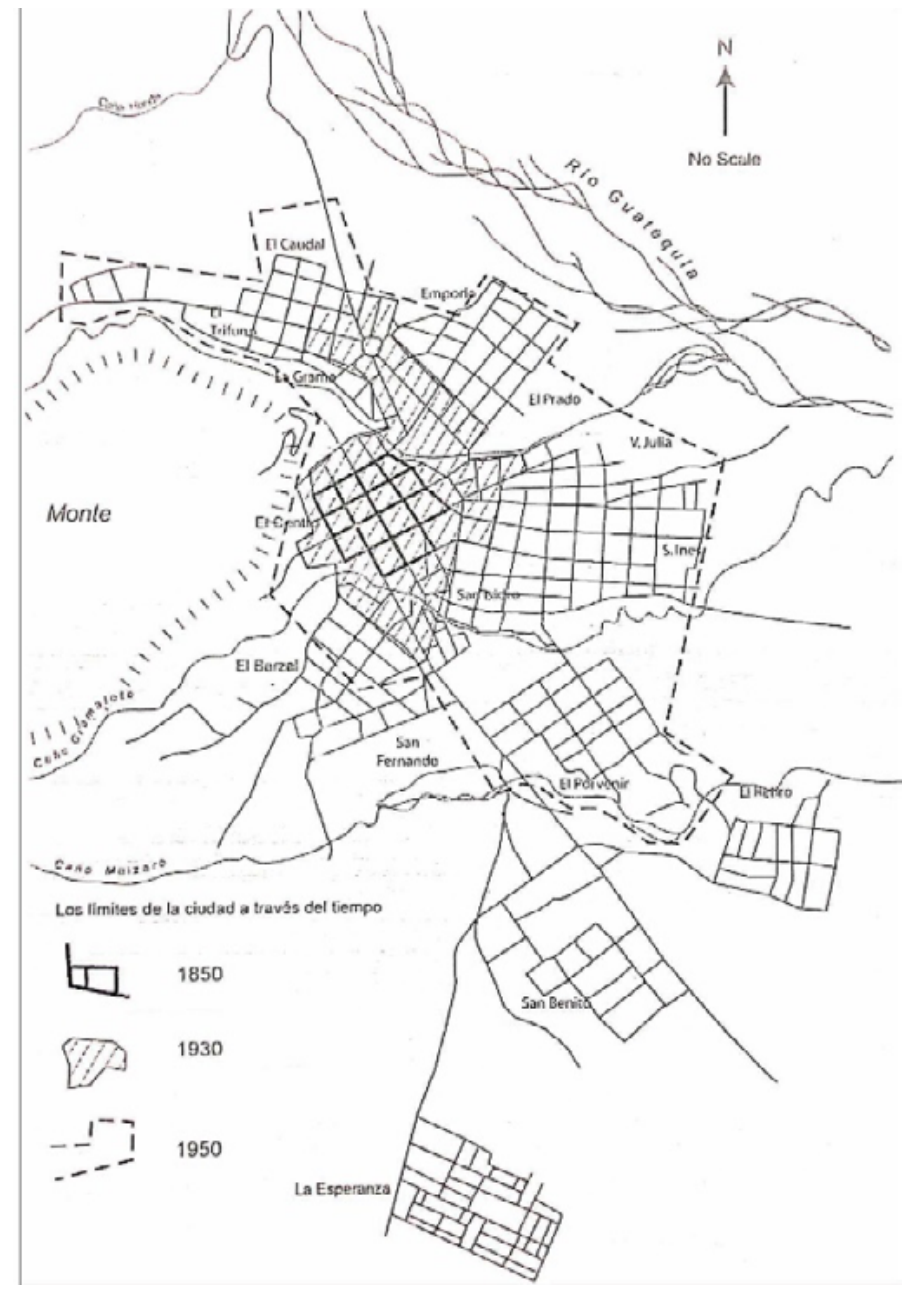

Fuente: Rausch (2011, p. 143).

El crecimiento de la mancha urbana de Villavicencio hasta 1950, aproximadamente, que hasta ahora se ha descrito tersitarios 43-Especial 18 el encuentro de caminos y elementos económicos que la atraviesan, se puede evidenciar en la figura 9, realizada por Rausch (2011), donde se hace una aproximación a tres diferentes etapas de crecimiento de la ciudad. Inicia en 1850 como punto originario oficial de la ciudad; en segundo lugar, se anota la década de 1930 con una primera explosión demográfica dada por los diferentes factores económicos y sociales definidos a lo largo del artículo, y, por último, la década de 1950 con la oleada de inmigrantes, desplazados de la violencia.

De esta manera, la ciudad se configuró paulatinamente a partir de anillos viales concéntricos al punto de origen histórico, sobre los que se daban los nuevos límites urbanos. Los ejes radiales que comunican dichos anillos y las nuevas porciones de ciudad que se generaban fueron también obras creadas bajo los principios modernos de eficiencia y desarrollo. Es a partir de estos que hoy en día la ciudad continúa su crecimiento. A su vez, el auge del transporte de ganado sumado a la alta migración de campesinos llaneros, que tuvo la ciudad, comienzaron a plantear la necesidad de una identidad villavicense por parte de sus dirigentes, quienes emprendieron acciones para convertir a la ciudad en la principal representante de la cultura llanera por medio de festivales y eventos - como el de la canción folclórica, reinados regionales, torneos de joropo-y la creación de centros de estudio y difusión de la cultura, ente otros.

La necesidad de estas acciones es continua en el tiempo debido a que la 
ciudad mantiene su carácter de receptora de migrantes; sin embargo, existen ciertas rencillas y sentimientos de superioridad étnica por parte de los que se consideran establecidos (Elias, 1990) - aunque también sean inmigrantes o hijos de inmigrantes - con los recién llegados, sin importar sus condiciones socioeconómicas. Hay dos tipos de personas que intentan resaltar más su "llaneridad". Por un lado, las clases de menor poder adquisitivo que normalmente vienen de los campos llaneros y han estado en contacto con las costumbres campesinas de la región, quienes, al llegar a la ciudad, pretenden continuar con su estilo de vida. Algunos de ellos mantienen con orgullo el uso del sombrero, el machete y, en muchos casos, no usan calzado - a la usanza de los viejos llaneros-. Por otro lado, están los dirigentes políticos, que por haber tenido algún tipo de contacto con el llano (por sus propiedades rurales), asumen la actitud populista que produce su asimilación con la cultura folclórica del lugar al usar sombreros, hablar como criados de una hacienda, adorar y promocionar la música llanera, los "parrandos" y el coleo como deporte "autóctono"; compiten por promover constantes festivales y cabalgatas por la ciudad, produciendo y reproduciendo una imagen falsa de esta.

En el fondo, Villavicencio es un lugar donde cohabitan diversas culturas colombianas, con costumbres de múltiples regiones, lo que genera una sociedad compleja, ecléctica y difícil de entender.

\section{Ciudad intermedia y posmoderna}

Según el Banco Interamericano de Desarrollo (BID), Colombia es un país con una fuerte apropiación del territorio, lograda a través de lo que oficialmente dicho organismo denomina ciudades intermedias con las que, se dice, podría mitigar los problemas de las grandes ciudades y alcanzar un desarrollo sostenible si se refuerzan políticas en tal sentido. Según informes de dicha entidad, en Colombia existían 57 ciudades intermedias entre cien mil y un millón de habitantes en 2014, a diferencia de 1985 cuando había 30, y en ellas habita el $40 \%$ de la población del país (Torres Arzayús \& Caicedo Cuervo, 2015).

Ahora bien, de acuerdo con la Ley 617 del 2000 y la Ley 1551 del 2012 es posible categorizar los municipios colombianos desde especiales (con más de $500 \mathrm{mil}$ habitantes), hasta la sexta categoría conformada por los de menos habitantes. En específico, la última de las leyes mencionadas los categoriza en tres agrupaciones: grandes, intermedios y básicos. En tal sentido, Villavicencio es categoría l dentro del grupo de los grandes municipios; en esta categoría se encuentran 18 ciudades colombianas que, junto con las 17 de categoría 2, y las 22 de categoría 3, forman el gran núcleo urbano enmarcado por el BID como ciudades intermedias (Carmona Sánchez et al., 2014).

Es posible afirmar, a su vez, que las ciudades intermedias en Colombia no han superado la modernidad, periodo en el que tersitorias 43-Especial 
2 Formulado en el 2015 con vigencia hasta 2027 (o hasta cuando se apruebe la reforma estructural) por medio del Acuerdo Municipal $N^{\circ} 287$ de 2015, por medio del cual se adopta el Nuevo Plan de Ordenamiento Territorial (POT Norte) del Municipio de Villavicencio y se dictan otras disposiciones.

${ }^{3}$ Lo cual puede ser un factor importante para comprender por qué en el POT se especifican los conjuntos cerrados como una tipología exclusiva, a diferencia de los barrios tradicionales que no pasan de estar nombrados.

\section{territorias 43-Especial}

el urbanismo era una manera ordenada de planificar las ciudades. Sin embargo, la posmodernidad, entendida por Harvey (1990) como un tejido fraccionado, una mezcla de tiempos en un espacio autónomo, es una caracterización que se adecúa a la ciudad de Villavicencio en la actualidad. Tal como lo anota Raffestin (2011), la idea de que la contemporaneidad trajo un afán de mimetismo y una pérdida de diferencias - al menos superficialmenteque se visualiza dramáticamente en los fragmentos cerrados de vivienda existentes en Villavicencio, la ciudad pasa de ser una tradicional (más o menos conectada), determinada por la heterogeneidad en la premodernidad a una planificada desde el Estado, con base en grandes intervenciones urbanas y en la separación de usos $\mathrm{y}$ actividades propias de la modernidad.

Villavicencio, en la actualidad, está mezclada pero apropiada por el mercado, que sacrifica la historia y todo lo indeterminado por algo más previsible, o en términos de Pérez (2004): por una producción aséptica del espacio con máximos beneficios económicos. Es posible asumir el concepto de collage para tener una imagen contemporánea de ella, que se acentúa con la liberalización del mercado, la globalización y la aparición de los fragmentos de vivienda. El análisis de este fenómeno se hace importante en ciudades intermedias, donde prácticamente es la única forma de producción de territorio privado, especialmente en una ciudad como Villavicencio si se tienen en cuenta sus características económicas, sociales, políticas e históricas.

Llegados a este punto, cabe señalar que su plan de ordenamiento territorial $(\text { РОT })^{2}$ continúa centrando sus esfuerzos en planificar una ciudad ante todo segura, ${ }^{3}$ pero además, competitiva, turística y de servicios. Se encuentra entonces una hoja de ruta, como el mismo plan se denomina, en la que se descartan de plano las actividades secundarias o industriales. Este se centra en actividades primarias: extractivas-agrícolas, y terciarias, a través del turismo y los servicios. Esto no es una novedad para la ciudad porque, como ya se mostró ampliamente, nunca contó con una aglomeración de industrias o algo similar.

Lo novedoso de dicho plan se encuentra en algunas estrategias planteadas desde el punto de vista formal, como es la llamada "ciudad con paisaje llanero" que intenta mantener la idea de la "llaneridad". Así mismo, la intención de promover la creación de un área metropolitana que busca poner a la ciudad en el mapa de este tipo de configuraciones, aunque sin una explicación profunda sobre los impactos que esto puede tener, más allá de ser parte de un grupo de ciudades que dominan a las de su entorno, apropiándose de su espacio, su identidad y en la mayoría de los casos, generando una desterritorialización que termina siendo negativa para el municipio dominante y para los dominados. Normalmente, los mayores 
beneficiados de estas políticas son las empresas constructoras que encuentran terrenos a menor valor y pueden continuar con sus lemas comerciales de ciudades naturales, de encuentros con el campo, de mayor espacio, etc. Esto no es una crítica a la planeación regional por proponer esta intensión, la cual es absolutamente necesaria para una articulación coherente entre los diferentes territorios que conforman el llano e incluso con la capital, pero no tiene nada que ver con la generación de área metropolitana y la absorción de ciudades históricas que siempre han tenido una mayor y verdadera relación con las actividades propias del llano, al menos desde la época de la colonia.

Desde otro sentido, se resalta la idea de plantear un municipio policéntrico, mediante la generación de diferentes actividades en otras partes de la ciudad diferentes al centro fundacional, lo cual supone una preocupación por la magnitud de la ciudad, producto de la migración producida por el desplazamiento. Es decir, Villavicencio ya no debe plantearse solamente en términos de ciudad concentrada y densa, que utiliza una estrategia que ha nacido en otras latitudes con un relativo éxito, pero con claras diferencias en cuanto al potencial económico y al desarrollo que no se tienen en esta ciudad.

En definitiva, el plan propone estrategias que podrían llegar a ser útiles y las herramientas necesarias para lograrlo si se cuenta con recursos y políticas continuadas y coherentes, algo que realmente no ha sido la característica ni de esta ni de la mayoría de las ciudades en Colombia. Sin embargo, el POT no presenta propuestas de acción con las cuales se desglose e indique cómo se van a lograr estas buenas intenciones, se intenta poner a la ciudad a la vanguardia de las ideas, lo cual es lo mínimo que se le puede pedir a una normativa que pretende predecir o adelantarse al futuro, pero, bajo una lectura profunda y juiciosa, no se ve cuál será el camino para llegar desde lo que se es a lo que se planea como ciudad.

\section{Reflexión final}

Una mirada metafórica de la mano sirve como reflexión final de este recorrido por la historia de Villavicencio. No solo porque es el símbolo de la ayuda, la protección y la acogida - lo que para muchas personas ha sido la ciudad a lo largo de su historia-, sino porque, además, refleja físicamente un eje que converge en un refugio que luego se divide en múltiples ramificaciones hacia otros lugares.

El concepto de eje puede concluir y fundamentar el surgimiento y desarrollo de Villavicencio. Es un vector sobre el cual giran dinámicas económicas, políticas y culturales que acogen una gran región en extensión y producción de diferentes elementos como el petróleo y el ganado $\mathrm{y}$, en los últimos tiempos, de turismo. Este concepto se materializa en todos los territarios 43-Especial 21 


\section{tersitarias} 43-Especial caminos que existen y han existido desde los anales de la historia, que llegan al mismo punto: el camino que conecta a dos partes del país con la capital de Colombia y con el mundo.

Villavicencio es a su vez la representante, la cara y la imagen más relevante de la cultura y la identidad llanera, sin ser precisamente un espacio diferente al de la mayoría de las ciudades modernas, donde reina la indiferencia, las urgencias de la cotidianidad y la búsqueda de la individualidad a través del encerramiento y la pérdida de las relaciones sociales en el espacio urbano, las cuales quedan relegadas al interior del hogar, los centros comerciales, los conjuntos cerrados y, en otras ocasiones, a las fincas de recreo que, nuevamente, no tienen nada que ver con lo que se supone que es y significa el llano y su folclor.

Se puede inferir que la cultura llanera en Villavicencio es una invención con réditos políticos y económicos desde el turismo, debido a que aún, en tiempos modernos, la población urbana no tiene mucha relación con las actividades ganaderas o agrícolas del sector rural y, en muchos casos, ni siquiera son oriundos de la región. Por el contrario, la vida de la ciudad se ha nutrido de los aventureros, los expulsados y los comerciantes que, venidos de otras regiones, se instalan y hacen suyo el lugar, adoptando las costumbres que, se supone, deben tener.

Revisando las últimas décadas de la historia de la ciudad, se observa el carácter conservador de sus políticas urbanas en la medida en que siempre se hace un gran énfasis en tratar de conservar rasgos histórico-culturales, además de la seguridad. Sin embargo, la ciudad ha crecido con sus dinámicas propias de migración, informalidad y espontaneidad, en las que se prioriza el poder económico y político sobre los derroteros propuestos por planes preestablecidos.

La ciudad de la modernidad, que se mostró en este documento, se construyó a partir de apropiaciones del espacio mediante la aprobación de planes urbanos, donde estaban las vías, el manzaneo y el loteo para que posteriormente se materializaran las viviendas. Actualmente, se cuenta con una ciudad en la que se construyen básicamente dos perspectivas: la pública, que hace sus aportes en asocio con constructoras privadas, que realizan viviendas de interés social o prioritario, en lugares apartados del centro de la ciudad, especialmente por su menor valor, creando guetos de pobreza. Por otro lado, están las intervenciones privadas que, en materia de vivienda, se dedicaron exclusivamente a crear conjuntos de vivienda cerrados por vallas en los que aparecen diferentes guetos, cada uno según el estrato al que vaya dirigido el fragmento.

Finalmente, la ciudad que se planea no busca retomar las ideas de centralidad y densidad, sino más bien asumir el desmedido crecimiento a través del policentrismo y la adopción de un área metropolitana creada artificialmente 
mediante el mejoramiento de vías y la reducción de la identidad de cada uno de los lugares que se piensa incorporar bajo el dominio de la ciudad capital del departamento.

\section{Referencias}

Alcaldía de Villavicencio. (2016). Unidos podemos. http://www.villavicencio. gov.co/MiMunicipio/Paginas/Informacion-del-Municipio.aspx

Aprile-Gniset, J. (1992). La ciudad colombiana. Siglo XIX y Siglo XX. Fondo de Promoción de la Cultura.

Baquero Nariño, A. (1990). El caso llanero, Villavicencio: aproximación al modelo de crecimiento sin desarrollo. Editorial Siglo XX.

Barbosa Estera, R. (1988). Llanero, conflicto y sabana: historias presentes. En A. Baquero Niño (Ed.), Los Llanos, una historia sin fronteras (pp. 354-355). Academia de Historia del Meta.

Carmona Sanchez, C., Supelano González, D., \& Osejo Villamil, I. (2014). Tipologias departamentales y municipales: una propuesta para comprender las entidades territoriales colombianas. Departamento Nacional de Planeación - Dirección de Desarrollo Territorial Sostenible. https://colaboracion.dnp.gov.co/CDT/Estudios\%20 Econmicos/2015may28\%20Tipologias.pdf
Duarte, C. A., \& Vargas, M. V. (2013). Modelo de ciudad en Colombia. https:// ciudadencolombia.wordpress.com/

Elias, N. (1990). La sociedad de los individuos (J. A. Alemany, Trd.). Península.

Espinel Riveros, N. (1989). Villavicencio, dos siglos de historia comunera. 17401940. Gráficas Juan XXIII.

Franco, L. G. (2017). Contexto y pretexto de la arqueología en los Llanos Orientales de Colombia. Boletín de Antropologia, 32(54), 276-297. https://doi.org/10.17533/udea.boan. v32n54al2

Gómez López, A. J., \& Cavalier de Ferrero, I. (1998). Las sociedades indigenas de los llanos: sistemas económicos y características socio-culturales. http:// bdigital.unal.edu.co/7337/1/ las_sociedades_indigenas_de_los_llanos_AUGUSTO_J.pdf

Gutiérrez de Alba, J. M. (1871). Excursión a los llanos de San Martín. https://www.banrep.gov.co/impresiones-de-un-viaje/index.php/viajes/ index? view $=$ excursion-llanos

Harvey, D. (1990). La condición de la posmodernidad. Investigación sobre los orígenes del cambio cultural (M. Eguía trd.). Amorrortu.

Instituto de Turismo del Meta. (2014). Informe de gestión 2014. http:// www.turismometa.gov.co/transparencia-y-acceso-a-la-informacion/ doc_download/161-informe-gestion-2014.html territarios 43-Especial 


\section{tersitarias} 43-Especial
Lefebvre, H. (2013). La Producción del espacio. Capitán Swing.

Melo, J. O. (1978). Historia de Colombia. La dominación Española. La Carreta.

Ojeda, T. (2000). Villavicencio entre la documentalidad y la oralidad, 18801980. Edición Corocora Orinoquense.

Ortega Ricaurte, E. (1943). Villavicencio 1842-1942. Monografía histórica. Prensas de la Biblioteca Nacional.

Pérez Ángel, H. P. (1988). Impacto de las misiones religiosas y de las guerras de independencia en la construcción de pueblos y ciudades coloniales en los llanos. http://bdigital.unal.edu.co/7338/1/ IMPACTO_DE_LAS_MISIONES_ RELIGIOSAS_Y_DE_LAS_GUERRAS_DE_INDEPENDENCIA_ EN_LA_CONSTRUCCIÓN_DE_ PUEBLOS_Y_CIUDADES_COLONIALES_EN_LOS_LLANOS.pdf

Pérez, F. (2004). Prácticas y representaciones de la vida barrial. (Tesis de grado, Universidad Academia de $\mathrm{Hu}-$ manismo Cristiano, Chile). http:// bibliotecadigital.academia.cl/handle/123456789/195

Raffestin, C. (1986). Ecogenèse territoriale et territorialité. En F. Brunet (Ed.), Espaces, jeux et enjeux (pp. 175-185). Fayard \& Fondation Diderot. http:// archive-ouverte.unige.ch/unige:4419

Raffestin, C. (2011). Por una geografía del poder (Y. Villagómez Velázquez trd.). El Colegio de Michoacan.
Rausch, J. M. (1954). Una frontera de la sabana tropical los llanos de Colombia: 1531-1831. Banco de La República.

Rausch, J. M. (2011). De pueblo de frontera a ciudad capital: la historia de Villavicencio, Colombia, desde 1842 (M. V. Mejía Duque, Trd.). Universidad de Los Llanos.

Rueda Enciso, J. E. (1987). Cravo: La antigua Hacienda Jesuítica. Revista Lámpara, 25(105), 7-15.

Ruiz Churión, J. (1992). Mexa Grameta Metacuya El Meta. Casa de la Cultura de Villavicencio.

Salamanca Uribe, J. (2009). Villavicencio, la ciudad de las dos caras. Revista Credencial Historia, (231). http://www. banrepcultural.org/biblioteca-virtual/ credencial-historia/numero-231/villavicencio-la-ciudad-de-las-dos-caras Secretaría de Planeación Municipal de Villavicencio. (2013). Sintesis diagnóstica Norte. Plan de Ordenamiento Territorial de Villavicencio.

Torres Arzayús, P., \& Caicedo Cuervo, C. J. (2015). Las ciudades intermedias con mayor potencial en Colombia: Un sistema de identificación. Banco Interamericano de Desarrollo. https:// publications.iadb.org/publications/ spanish/document/Las-ciudades-intermedias-con-mayor-potencial-en-Colombia-Un-sistema-de-identificación. pdf 